\title{
CORRESPONDENCE
}

These letters respond to the News Feature 'Closing arguments' (Nature 457, 650-655; 2009), about problems faced by laboratories funded by the US National Institutes of Health.

\section{Diversity of funding sources and topics is key to survival}

\section{SIR - Reduced funding and increased competition among a larger body of active researchers also affects countries other than the United States, and fields other than the biomedical sciences. \\ Here in the United Kingdom, \\ e-mail:brian.derby@manchester.ac.uk \\ Grant-writing offices would let scientists get on with research} those of us who use the Engineering and Physical Sciences Research Council (EPSRC) for funding have witnessed a similar scenario to that described in your News Feature: a smaller fraction of assessed grants are being funded and we have reached the stage where there is - for all practical purposes - a lottery to determine which of the many excellent proposals submitted will be successful.

The amount of money that is available for curiosity-driven research is also decreasing, as the government seeks to steer funding into areas of political priority. The response from the scientific community is, of course, to become more inventive about the potential applications of a given proposal.

I believe that the best way to maintain research activity is through diversity in both sources of funding and topic. You indicate that undue weight is given to National Institutes of Health funding (as opposed to general funding) in many US institutions as a requirement for tenure or promotion. This may further concentrate academics in attempting to access a finite pot, with a consequently reduced rate of success.

However, despite the disappointment that we may feel in not receiving enough funding to maintain our activity or research-group size at a desired level, we academics should recognize our privileged tenured position in times of economic hardship such as the present. Brian Derby School of Materials, University of Manchester, Grosvenor Street, Manchester M1 7HS

SIR - The present financial crisis is putting many early-career scientists in a complicated situation, as noted in your News Feature and the Editorial 'Crisis of confidence' (Nature 457, 635; 2009). I agree with the Editorial that "doctoral programmes should build better career counselling and training into their curricula from the start", but I also believe that universities cannot continue to expect professors to do research and apply for grants and patents, as well as teaching.

People often choose an academic career for the freedom and creativity of doing research. Overburdening them with administrative tasks means that their creativity is hardly used. One solution might be a 'grant-writing' office that would know all about the availability of grants, how they might apply to specific topics and what they should contain.

Cecile Perrault Department of Biomedical Engineering, McGill University, Montréal, Québec H3A 1A4, Canada e-mail: cecile.perrault@mcgill.ca

\section{We need more insight into what's worth paying for}

SIR - An economic argument can be made that growth depends on the creation of new markets being opened up by new technology. Personalized medicine provides an example of this, as do advances in medical instrumentation such as magnetic resonance imaging and laser eye surgery.

Balancing the need for increased spending to further economic growth with the need to spend more effectively during this economic downturn means that we must improve our ability to decide what research is worth funding. Simply lowering the percentage of funded grants won't cause this to happen by itself.

Effective spending depends on detailed peer review to assess applications properly. But the review quality necessary may be hard to realize in practice, because there is more and more research to review. The traditional rankings devised from impact factors don't take this kind of work into consideration - rather, they promote more writing, creating more work for reviewers. A better system would properly credit people for their review and assessment work so that money could be spent more effectively. William Gunn Genalyte Inc, 11760 Sorrento Valley Road San Diego, California 92121, USA e-mail: william.gunn@gmail.com

\section{Backlogged system in Australia shuts out new investigators}

SIR - The US situation may be worse than it once was. But it's still a big step ahead of Australia. Total health-related R\&D spending as a percentage of gross domestic product is roughly half that of the United States or the United Kingdom, according to the Organisation of Economic Co-operation and Development (Statistics and Indicators for 30 Countries OECD, 2007). Our biomedical fellowship scheme is backlogged to the point that the awards designed to support new principal investigators go mostly to well-established group leaders.
A recent survey of the medical research workforce in Australia highlights the level of anxiety and discontent over poor careerdevelopment opportunities and lack of funding (M. Kavallaris et al. Med. J. Australia 188, 520-524; 2008). In the preceding five years, for example, $6 \%$ of respondents had already left active research; $73 \%$ were considering leaving. This presents a clear challenge for recruitment and retention of a highly skilled workforce.

To keep Australian science at the leading edge, we need to maintain the flow of fresh ideas by ensuring opportunities for both new and established investigators. The new US administration has recognized the loss of careerdevelopment opportunities caused by underfunding. Australia runs the risk of failing to capitalize on significant government investments made so far. The recent announcement of a federal fellowship scheme for mid-career researchers hints at a potential improvement. But the near-term prospects for aspiring new investigators and those returning from overseas are not promising.

Darren Saunders Department of Pathology \& Laboratory Medicine, University of British Columbia; and Molecular Oncology \& Breast Cancer Program, BC Cancer Research Centre, Vancouver, BC V5Z1L3, Canada e-mail:dsaunders@bccrc.ca

In February 2009, the director of the US National Institute of Neurological Disorders and Stroke moved the institute's funding cut-off for grant applications from the 10th to the 11th percentile after a re-evaluation of financial obligations. The change meant that Darcy Kelley (quoted in this News Feature) and another seven investigators whose applications had fallen below the cut-off in recent funding rounds were fundedEditor, Nature.

Further discussion is welcome at http://tinyurl.com/cf59fq. 